\title{
Sequência didática de gêneros orais formais nos anos finais do ensino fundamental: a exposição oral em foco
}

\author{
Karen Francis Bellomo Ringis ${ }^{1}$ \\ Ana Sílvia Moço Aparício ${ }^{2}$
}

\begin{abstract}
RESUMO
O objetivo deste trabalho foi investigar o processo de construção colaborativa de uma sequência didática do gênero exposição oral em aulas de Língua Portuguesa do $7^{\circ}$ ano de uma escola estadual paulista. A investigação segue a abordagem qualitativa, de cunho colaborativo intervencionista, considerando a parceria entre a pesquisadora e a professora colaboradora. A fundamentação teórica da pesquisa está embasada, sobretudo, nas contribuições dos estudos sobre ensino da língua materna do grupo de Didática da Língua Materna da Universidade de Genebra. Os resultados evidenciam que a exposição oral é um gênero que os alunos não dominam e, em vista disso, são necessárias intervenções didáticas que permitam reflexão acerca da relevância em associar os recursos linguísticos, prosódicos e cinésicos aos elementos multissemióticos que interagem e se integralizam no desenvolvimento das exposições orais em contextos formais públicos.
\end{abstract}

PALAVRAS-CHAVE: Exposição oral. Gêneros orais formais. Sequência didática.

Didactic sequence of formal oral genres in the final years of elementar school: the oral exhibition in focus

\footnotetext{
${ }^{1}$ Mestre. Universidade Municipal de São Caetano do Sul. (USCS). São Caetano do Sul, São Paulo, Brasil. Orcid: https://orcid.org/0000-0002-0329-9111. E-mail: karen.ringis@prof.uscs.edu.br.

${ }^{2}$ Doutorado. Universidade Municipal de São Caetano do Sul. (USCS). São Caetano do Sul, São Paulo, Brasil. Orcid: https://orcid.org/0000-0001-6725-5372.E-mail. anaparicio@uol.com.br.
} 


\begin{abstract}
The objective of this research was to investigate the process of collaborative construction of a didactic sequence of oral exposition genre, in Portuguese language classes of $7^{\text {th }}$ grade from a São Paulo state school. The carried out research follows the qualitative approach, of a collaborative interventionist nature, considering a partnership between the researcher and the collaborating teacher. The theoretical basis of the research is based essentially on the contributions of studies related to the teaching of the mother language, of the Didactics of the Mother Language group at the University of Genebra. The results show that oral exposure is a genre that students do not master and, in view of that, didactic interventions are necessary to allow reflection on the relevance in associating linguistic, prosodic and kinetic resources with multisemiotic elements that interact and integrate in the development of oral exhibitions in formal public contexts.
\end{abstract}

KEYWORDS: Oral exposure. Formal oral genres. Following teaching.

Secuencia didáctica de géneros orales formales em los últimos años de la escuela primaria: la exposición oral em foco

\title{
RESUMEN
}

El objetivo de esta investigación fue investigar el proceso de construcción colaborativa de una secuencia didáctica del género exposición oral en el aula de Lengua portuguesa a estudiantes de séptimo grado de una escuela estatal de São Paulo. La investigación realizada sigue el enfoque cualitativo, de carácter intervencionista colaborativo, considerando una asociación entre el investigador y el profesor colaborador. La base teórica de la investigación se basa, essencialmente, en las contribuciones de los estudios relacionados con la enseñanza de la lengua materna, del grupo Didáctica de la Lengua Materna en la Universidad de Ginebra. Los resultados muestran que la exposición oral es un género que los estudiantes no dominan y, en vista de eso, son necesarias intervenciones didácticas para permitir la reflexión sobre la relevancia en asociando recursos lingüísticos, prosódicos y cinéticos con elementos multisemióticos que interactúan e integran en el desarrollo de exposiciones orales en contextos públicos formales.

PALABRAS CLAVE: Exposición oral. Géneros orales formales. Secuencia didáctica. 


\section{Introdução}

Um dos aspectos que nos últimos anos vem chamando a atenção dos educadores, especialmente dos professores de Língua Portuguesa, refere-se às questões voltadas à prática da oralidade, visto que muitas dificuldades surgem em situações mais formais que exigem exposição oral.

Levando-se em consideração que a escola também é lugar para aprender a oralidade, faz-se necessário tornar a exposição oral uma atividade natural e até prazerosa para os alunos, já que se expressar bem é uma exigência deste século. Então, como ensinar o aluno a se expressar oralmente, de forma coerente, a fim de exprimir claramente suas ideias?

Vale ressaltar que, no ambiente escolar, os gêneros textuais orais, quando são trabalhados, quase sempre têm como destino a aprendizagem da escrita. A leitura em voz alta, por exemplo, é a atividade oral mais frequente em sala de aula, porém, não se trata de um texto oral e sim, como afirma Dolz; Schneuwly; Haller (2004, p.167), de uma “escrita oralizada”. Isso, como defendem os autores, é reflexo da supervalorização da escrita em detrimento da oralidade não apenas na escola, como também fora dela.

Desde os Parâmetros Curriculares Nacionais (PCN) - Língua Portuguesa, anos finais do Ensino Fundamental, e mais recentemente com a Base Nacional Comum Curricular (BNCC), as diretrizes de trabalho estabelecidas para o ensino da Língua Portuguesa apontam a necessidade de se trabalhar com a linguagem oral, visto que os educandos, nas mais variadas situações do exercício da cidadania em que se inserem, serão aceitos ou discriminados, à medida que forem capazes de se adequar ou não às diferentes modalidades do gênero oral.

Nesse sentido, a partir de contextos de produção oral específicos, é possível desenvolver nos discentes a capacidade de se expressarem oralmente de maneira adequada em diferentes situações orais públicas. Para tal, defendemos que o dispositivo Sequência Didática (daqui por 
diante, SD), idealizado pelos pesquisadores do campo da Didática da Língua Materna da Universidade de Genebra (SCHNEUWLY; DOLZ, 2004), é um instrumento valioso.

Tendo isso em vista, neste artigo, discutimos resultados de uma pesquisa de mestrado que investigou contribuições do uso do dispositivo SD de gêneros textuais para o desenvolvimento das capacidades de linguagem oral formal dos alunos, nas aulas de Língua Portuguesa, nos anos finais do Ensino Fundamental. Mais especificamente, focalizamos aqui o processo de construção colaborativa da SD pelo professor de língua portuguesa e pela pesquisadora.

Primeiramente, apresentamos o referencial teórico que embasou a pesquisa; na sequência, explicitamos o percurso metodológico do trabalho; por fim, discutimos os resultados do trabalho, com base nos dados do desenvolvimento da SD.

\section{Os gêneros orais formais}

Todas as atividades praticadas diariamente que envolvem linguagem, desde as mais simples, como uma saudação, até as mais complexas, da esfera do trabalho ou científica, se apoiam em vários gêneros discursivos, orais ou escritos. Consequentemente, todas as falas, cotidianas ou formais, se estruturam em torno de gêneros de discurso, definidos por Bakhtin (2006), como formas relativamente estáveis de enunciados, os quais se moldam a determinadas situações comunicacionais.

De acordo com Marcuschi (2007, p.17), "oralidade e escrita são práticas e usos da língua com características próprias, mas não suficientemente opostas". Fala e escrita não se configuram em uma dicotomia, pois a escrita não consiste em uma representação da fala. Trata-se de um continuum. Em relação à oralidade, em contextos de comunicação formal pública, algumas questões influenciam não só a expressão oral como a escrita também, entre elas: variação linguística, situação comunicacional, contexto, subjetividade. Tal fato fica claro ao se 
notar que, mesmo inconscientemente, os usuários da língua sabem que devem se portar, tanto na fala quanto na escrita, de determinada maneira em relação ao interlocutor que estão interagindo. Essas situações exigem posturas linguísticas e sociais específicas, as quais se definem a partir de critérios da formalidade ou informalidade, e é papel da escola sistematizá-las. Como ressalta Marcuschi (2007, p.25),

A formalidade ou a informalidade na escrita e na oralidade não são aleatórias, mas se adaptam às situações sociais. Essa noção é de grande importância para perceber que tanto a fala como a escrita têm realizações estilísticas bem variadas com graus de formalidade diversos. Não é certo, portanto, afirmar que a fala é informal e a escrita é formal.

Dolz e Scheneuwly (2004) afirmam que os gêneros orais formais assumem variadas características em seu funcionamento e que o grau de formalidade de cada um deles é totalmente dependente do lugar em que ocorre a comunicação. São exemplos de gêneros orais formais: exposição oral, entrevista profissional, debate, homilia, palestra, entre tantos outros.

Nesse sentido, Dolz, Scheneuwly e Haller (2004) defendem a introdução da oralidade como objeto de ensino na escola, e propõem o trabalho com fenômenos de textualidade oral em sintonia com as situações reais de comunicação, considerando-se diferentes níveis da atividade de linguagem, tornando, dessa forma, o ensino mais significativo.

\section{Os gêneros orais na escola}

Os Parâmetros Curriculares Nacionais (BRASIL, 1998) já recomendavam o trabalho com a oralidade em sala de aula, priorizando os usos mais formais, inclusive como instrumento para propiciar a cidadania. De acordo com o documento, somente na escola os alunos terão a possibilidade de aprender os procedimentos apropriados de fala e 
escuta, em contextos públicos, se ela tomar para si a tarefa de promovêla. Mais recentemente, a BNCC (BRASIL, 2017) retoma as orientações dos PCN e define como eixos do ensino de Língua Portuguesa as práticas de oralidade, leitura/escuta, produção (escrita e multissemiótica) e análise linguística/semiótica.

Contudo, definir claramente qual linguagem oral trabalhar na escola torna-se uma difícil tarefa para o professor. Este, por vezes, encontra-se frente a vários questionamentos: "Como tornar o oral ensinável? Que oral tomar como referência para o ensino? Como torná-lo acessível aos alunos? Quais dimensões escolher para facilitar a aprendizagem?" (SCHNEUWLY; DOLZ, 2004, p. 151).

Pesquisadores do grupo de Genebra como Schneuwly e Dolz (2004) e também muitos brasileiros como Goulart (2005, 2017), Magalhães (2006), Guimarães; Souza (2018), entre outros, preocupados com um ensino da língua que possibilite aos alunos desenvolverem capacidades de linguagem oral que lhes permitam fazer uso competente da língua nas mais diversas situações comunicacionais formais públicas, defendem que a SD pode ser um instrumento valioso.

A SD representa um conjunto de atividades planejadas e organizadas em torno de um determinado gênero textual oral ou escrito, com o propósito de desenvolver nos alunos capacidades de linguagem no decorrer do processo de aprendizagem (SCHNEUWLY; DOLZ, 2004).

Figura 1 - Esquema da sequência didática

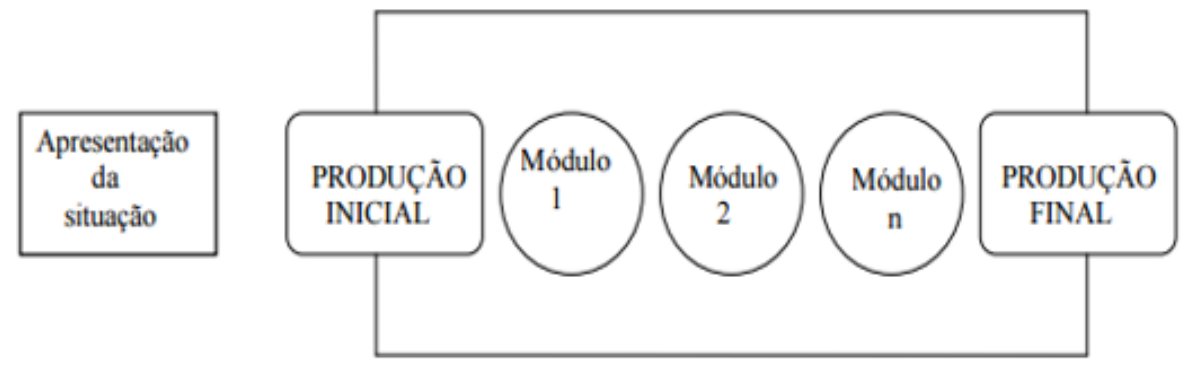

Fonte: (DOLZ; NOVERRAZ; SCHNEUWLY, 2004, p. 98). 
Na primeira etapa da SD, chamada "apresentação da situação", o professor descreverá detalhadamente a tarefa de produção, oral ou escrita, que os alunos deverão realizar. Em seguida, na "produção inicial", elaborarão a primeira atividade, e irão explicitar para si e professor as noções que têm dessa tarefa. O professor irá diagnosticar as dificuldades apresentadas pelos alunos, por meio de uma avaliação formativa e os problemas oriundos serão trabalhados nas atividades dos "módulos". Assim sendo, os módulos compõem uma sequência de oficinas com objetivos claros, visando trabalhas aspectos em que os alunos apresentaram ter dificuldades na primeira produção. Após os módulos, a SD encerra-se com a "produção final", ocasião em que os alunos colocarão em prática os conhecimentos adquiridos nos módulos (APARÍCIO; ANDRADE, 2016).

Dessa forma, a SD é considerada um instrumento importante para o ensino de línguas, por meio de diferentes gêneros textuais que circulam socialmente, visto que permite aos alunos conhecerem tais gêneros, compreendê-los, dominá-los e utilizá-los em situações comunicativas efetivas e contribui para que o professor possa acompanhar, de forma mais efetiva, o desenvolvimento das capacidades de linguagem de seus alunos. (DOLZ, GAGNON; DECÂNDIO, 2010).

Tendo isso em vista, adotamos em nossa pesquisa o procedimento da SD para o trabalho com o gênero exposição oral em uma turma de $7^{\circ}$. ano de uma escola pública da rede estadual da região do grande $\mathrm{ABC}$ paulista.

\section{Procedimentos metodológicos da pesquisa}

Este trabalho seguiu os pressupostos da pesquisa qualitativa, de cunho colaborativo intervencionista, com intervenções planejadas intencionalmente, realizadas colaborativamente pelo professor e pesquisador em sala de aula, com a finalidade de promover avanços no objeto de estudo e no desenvolvimento profissional docente (Damiani, 2012). 
No desenvolvimento da pesquisa, foi construída a parceria da pesquisadora com a professora colaboradora, no planejamento e desenvolvimento da SD. Os dados desta etapa foram obtidos por meio de gravações em vídeo das interações em sala de aula: professor-aluno, aluno-aluno, além de registros em diário de campo. As gravações em vídeo das atividades em sala de aula foram realizadas pela pesquisadora, pelo celular, buscando captar as falas e movimentações dos alunos nos momentos das exposições orais, de forma que os alunos não se sentissem intimidados com a filmagem durantes as atividades. Por fim, todo material coletado nesse processo foi criteriosamente analisado à luz do referencial teórico da pesquisa.

A pesquisa foi desenvolvida em uma escola pública da rede estadual de São Paulo, localizada na cidade de Ribeirão Pires, na região do Grande ABC paulista, ao longo de três meses do primeiro semestre letivo de 2019, tendo como participantes uma professora de Língua Portuguesa (professora colaboradora) e a turma de $7^{\circ}$ ano composta por 32 alunos, com idades entre 11 a 13 anos.

\section{A construção do modelo didático do gênero exposição oral}

Importante salientar que, para o trabalho com a SD, Dolz e Schneuwly (2004) propõem a construção de um modelo didático que forneça um conjunto de dimensões ensináveis do gênero, o qual permitirá ao professor realizar o levantamento do que se pode ser ensinado do gênero e que o guiará na elaboração da SD. Seu objetivo é orientar o professor nas práticas do ensino da Língua e ajudá-lo a acompanhar o desenvolvimento das capacidades de linguagem dos alunos.

Conforme Aparício e Andrade (2016), trata-se de um trabalho complexo, o qual antecede e orienta a construção da SD, e necessita que o professor apresente domínio dos conteúdos a serem ensinados e promova a melhor triagem dos aspectos do gênero a serem trabalhados, 
moldando-se às situações de aprendizagens, de acordo com as capacidades dos alunos. As autoras ressaltam a importância de o professor se aprofundar nos estudos do gênero a ser trabalhado, buscando, por exemplo: os saberes teóricos a seu respeito; as práticas sociais de referência, de uso do gênero, que emergem em diferentes situações reais de comunicação; os conteúdos típicos do gênero e as diferentes formas de mobilizar esses conteúdos; o estilo (características linguísticas e seus efeitos); as capacidades de linguagem dos alunos a serem desenvolvidas; as práticas escolares, as situações de ensino/aprendizagem vivenciadas com o estudo dos gêneros; as orientações de documentos oficiais, entre outros.

Em nossos estudos para a construção do modelo didático do gênero, constatamos que a "exposição oral" é um gênero bastante requisitado em atividades nas escolas, também chamadas de "seminários", porém pouco trabalhado com vistas ao desenvolvimento de competências orais relacionadas a situações formais de fala, que requerem um planejamento.

Para Gomes-Santos (2012, p.15), "a exposição é uma ação conjunta, o que supõe as habilidades de negociação de papéis, de atenção focada, de tomada e manutenção da fala, entre outras". Segundo esse autor, a realização da exposição por meio da fala do expositor engloba diversas semioses e também combina vários recursos semióticos, entre eles: os recursos paralinguísticos, como qualidade da voz, velocidade e ritmo da fala, pausa, entonação, etc. e recursos cinésicos (gestos, expressões faciais e corporais). Na exposição oral, esses recursos se complementam, ou seja, mantêm uma relação de interdependência. É a articulação desses recursos que promove a compreensão da exposição pelo público.

$\mathrm{Na}$ exposição oral, a expressão facial, incluindo o olhar, é também um recurso importante o qual ampara a elocução do expositor. A gestualidade é outro recurso bastante relevante na exposição oral, visto que ocorre em interação com os elementos do ambiente da exposição (lugares, iluminação, disposição das cadeiras, etc.), com as maneiras que os expositores se colocam 
no espaço e em relação ao auditório (ocupação de lugares, espaço pessoal, distâncias, contato físico, etc.), e também com os acessórios, cada vez mais tecnológicos, que o expositor utiliza ao realizar a exposição (slides em data show, vídeos da internet, imagens, etc.).

Com base em Goulart (2005; 2017), destacamos algumas características do gênero exposição oral:

- conteúdo temático: envolve temas amplos, geralmente ligados a questões de ensino, previstas na grade curricular, e sobre as quais os expositores se põem a construir um conhecimento para, depois, explicar a uma audiência;

- estilo verbal: relaciona-se a elementos de superfície linguística ligados ao tipo dissertativo, como: verbos no tempo presente ou no pretérito perfeito, frases declarativas, articuladores discursivos, discurso na primeira pessoa, marcadores de estruturação, organizadores estruturais e temporais, marcas de dêiticos;

- função sociocomunicativa: objetiva explicar, informar ou levar a audiência a refletir sobre determinado conteúdo temático produzido durante o trabalho de leitura e pesquisa do tema em estudo;

- condiçoes de produção: trata-se de um gênero bastante utilizado no ambiente escolar, sobretudo em atividades de apresentação de seminário, ou em eventos acadêmicos, tais como em congressos, workshops, palestras, simpósios, mas também pode ser encontrado em outras esferas de utilização da língua, a depender do ambiente sociodiscursivo onde tal gênero for utilizado e da atividade por meio da qual ele se configurará. O objetivo é ampliar os conhecimentos sobre determinado tema e expor à audiência (público) o que se aprendeu sobre tal tema.

Outro aspecto essencial na construção do modelo didático do gênero é a elaboração de uma grade de análise que forneça procedimentos mais claros e precisos para as avaliações das produções dos alunos. Sua finalidade é verificar as dificuldades e conhecimentos prévios dos alunos a fim de realizar intervenções, para, posteriormente, planejar o desenvolvimento da SD e também delinear as dimensões 
ensináveis do gênero. Tendo isso em vista, com base em Dolz, Gagnon e Decândio (2010), elaboramos a grade a seguir.

Quadro 1: Grade de análise do gênero exposição oral

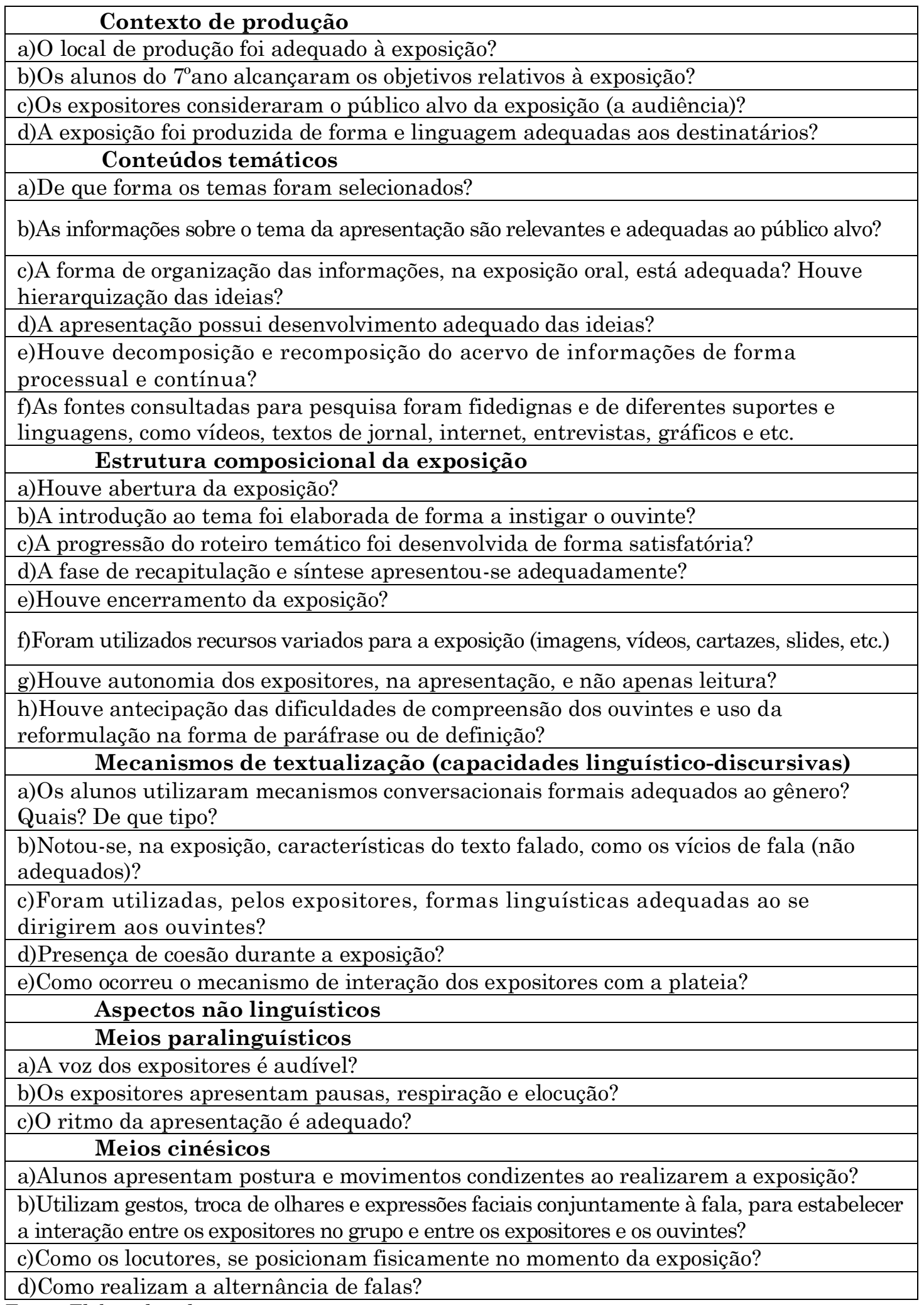

Fonte: Elaborado pelas autoras 
Com base, então, no conjunto de informações obtidas nos estudos sobre o gênero e sobre seu ensino, demos início ao desenvolvimento da SD em sala de aula, tal como descrito a seguir.

\section{O desenvolvimento da sequência didática do gênero exposição oral}

Seguindo o esquema da SD proposto por (SCHNEUWLY; DOLZ, 2004), iniciamos pela Apresentação da situação. Nessa etapa, iniciamos por uma roda de conversa com os alunos, perguntando a eles sobre como poderíamos trabalhar a oralidade em sala de aula. Eles propuseram várias formas, como teatro, entrevista, debate, exposição oral, até que, por unanimidade, ficou acordado que trabalharíamos a exposição oral. Em seguida, houve uma discussão para selecionar os espectadores, ou seja, quem seria o auditório, o público alvo da exposição. Os alunos inicialmente pensaram em se apresentar para os professores, coordenação, depois para os pais e, por fim, também em consenso e sempre mediados pela professora, decidiram que a plateia seria os alunos do $6^{\circ}$ ano. Logo após, ocorreu a formação de 6 grupos entre 5 e 6 participantes cada, também organizados pelos próprios alunos.

A definição dos temas que gostariam de expor também foi feita pela turma, tendo em vista o que consideraram ser de interesse do público alvo, os alunos do $6^{\circ}$. ano. Foram escolhidos, então, 6 temas, um por grupo, a saber: Bullying, O uso da tecnologia, Racismo, A importância dos exercícios físicos, Reciclagem e Convivência. Em seguida, a professora solicitou aos grupos que organizassem uma exposição oral relativa ao tema, para a semana seguinte, da forma como cada grupo pensasse que seria essa exposição. Intencionalmente, para seguir os propósitos da SD, os alunos não receberam nenhuma instrução para prepararem suas apresentações, ou seja, trabalharam mobilizando apenas seus conhecimentos prévios a respeito do que seria uma exposição oral dos temas escolhidos, para o público alvo estabelecido por eles. 
$\mathrm{Na}$ semana seguinte, conforme combinado, os grupos apresentaram a Primeira produção da exposição oral. O local da primeira produção foi a própria sala de aula, tendo os colegas da turma como audiência. Embora não tenha sido o verdadeiro local da situação comunicativa proposta, este foi adequado para os alunos terem uma noção do papel de enunciadores a um público receptor. Todos sabiam que esta seria uma primeira produção e que, após a análise dessa primeira apresentação, eles realizariam uma sequência de atividades para ampliar os conhecimentos sobre esse gênero oral e, então, realizariam a produção final apresentando para o público alvo, a turma do $6^{\circ}$. ano.

Para realizarmos a análise da primeira produção, consideramos a situação comunicativa proposta aos alunos e a grade de análise (Quadro 1). Vale ressaltar aqui que, para a análise, consideramos os dados de dois grupos representativos do conjunto. $\mathrm{Na}$ análise da primeira produção dos dois grupos, observamos que os alunos apresentaram muitas dificuldades na organização da exposição oral.

Quanto aos objetivos da exposição, todos os alunos apresentaram dificuldades para atingi-los. Por exemplo: realizaram leitura do conteúdo com cópia em mãos; os temas foram explorados de forma superficial; houve pouco entrosamento entre os membros do grupo; os alunos não evidenciaram domínio de conteúdo. Os grupos apresentaram-se sem levar em consideração a plateia. Muitos, ao falar, olhavam apenas para o chão. As trocas de fala entre os colegas ocorreram de forma bastante informal, carregadas de gírias e, em algumas ocasiões, palavrões.

Em relação ao conteúdo temático, as informações selecionadas sobre os temas foram muito superficiais, não evidenciando a relevância para os ouvintes, não consultaram várias fontes para colher as informações. Os alunos não se preocuparam em organizar as ideias para a exposição e, assim, não hierarquizaram as informações, tornando-as incompletas e soltas, dificultando o entendimento pela audiência. Além disso, inseriam tópicos que não se completavam, ocasionando um fluxo de informações 
desencontradas. Os grupos apresentaram um conteúdo quase que literalmente copiado de apenas uma fonte, sem evidências de um trabalho de organização de um acervo de informações.

Em se tratando das fases da exposição oral, os alunos não se apresentaram, nem realizaram saudação ao auditório, anunciaram o tema de forma bastante tímida. De fato, não assumiram o papel de expositores, nem criaram uma interação com seus colegas, que assumiam o papel de auditório. A introdução ao tema foi realizada, por ambos os grupos, de forma bem simples como, por exemplo: "O tema do nosso trabalho é ...", ou seja, os apresentadores não anunciaram os temas de modo a justificar sua relevância.

Não houve uma progressão lógica da exposição pelo fato de os grupos não terem elaborado um roteiro, A maioria dos alunos fez leitura, com cópia em mãos, sem fazer retomada de tópicos que já haviam sido mencionados; poucos dominaram o conteúdo e o desenvolveram com mínima autonomia e desenvoltura. Portanto, não houve, na produção inicial, a fase em que o expositor sumariza o conjunto de conteúdos expostos. Os alunos apenas leram e não se utilizaram de suportes visuais, como cartazes, slides, entre outros. Não foi anunciado o final da exposição, não houve agradecimentos ao auditório.

Em relação aos mecanismos conversacionais, os alunos não fizeram uso, por exemplo, de organizadores temporais de caráter mais formal: "agora vamos falar de...", "nesse sentido", “depois...", "em seguida...", "primeiramente..."; de introdução de exemplos: "por exemplo", "para exemplificar..."; de reformulações: "isto ê; "ou seja"; "quer dizer...".

Os alunos utilizaram marcadores conversacionais característicos de

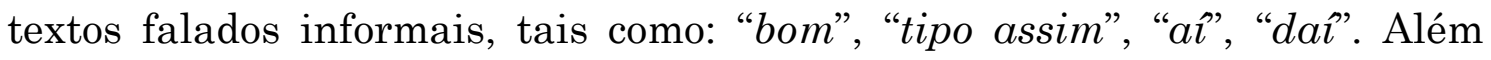
disso, foram utilizadas repetidas vezes expressões que indicam hesitação, por exemplo: "nê" e "tá", traços do processo de produção de fala em contextos informais do cotidiano. Também não houve coesão temática, os alunos não diferenciaram informações principais das secundárias, não houve sinalização que anunciasse a conclusão, como "portanto", "enfim”, etc. 
Quanto aos meios paralinguísticos, identificamos que o tom de voz dos alunos era praticamente inaudível e não apresentaram firmeza ao se exporem, pelo contrário, mostraram-se bastante desconfortáveis. Não houve um monitoramento das falas e essas particularidades importantes não foram trazidas para a exposição, prejudicando a clareza e coerência do conteúdo como um todo. O ritmo estava acelerado, dificultando o entendimento do auditório, visto que as falas estavam sem espaçamento, justamente pelo fato de os alunos estarem lendo ou com o texto decorado, tornando a apresentação do conteúdo monótona.

Por fim, no tocante aos meios cinésicos, os alunos não assumiram postura corporal ereta, não havia movimentação gestual de forma a enfatizar o que estava sendo enunciado. Uma aluna chegou a cobrir o rosto com as mãos. Não se notava direcionamento de olhar para o auditório, ou seja, quase não houve interação, comprometendo a socialização das informações com a plateia.

Os alunos se posicionaram um ao lado do outro, encostados à lousa, praticamente imóveis, não se colocavam em destaque no momento de falar. As trocas de falas não ocorriam de maneira natural. Alguns alunos necessitavam ser avisados que seriam o próximo a falar, o que demonstrava não estarem engajados na exposição, chegando até a se desentenderem no momento da fala.

Em síntese, a análise das produções iniciais, como prevíamos, evidenciou que os alunos têm muito pouco conhecimento sobre o que se espera na produção de um gênero oral formal, como a exposição oral. Tal resultado confirma as nossas reflexões iniciais de que a escola não tem trabalhado com esses gêneros, mas, por outro lado, foram essenciais para elaborarmos os módulos da SD.

Partindo-se, então, desse resultado da análise da primeira produção dos alunos, iniciamos o processo de planejamento e desenvolvimento dos módulos. Diante disso, foi necessário elaborar atividades que trabalhassem problemas de níveis diversos e que auxiliassem os alunos a refletirem acerca 
das particularidades da situação de produção e também dos diferentes aspectos característicos do gênero exposição oral.

Em síntese, os módulos foram compostos por várias atividades e exercícios, os quais permitiram aos alunos conhecerem recursos importantes ao domínio do gênero "exposição oral", possibilitando avanços em relação às dificuldades apresentadas nas produções iniciais. A seguir explicitamos as atividades trabalhadas em cada um dos 6 módulos que compuseram a SD.

No módulo 1, os grupos trabalharam a decomposição do acervo de informações. Isso aconteceu da seguinte maneira: em aula anterior cada grupo havia recebido 3 textos, relativos aos temas da exposição, retirados de suportes diferentes, ou seja, revista, jornal e blog. Nessa etapa, os alunos, em seus grupos, trabalharam, inicialmente, as habilidades relativas à leitura dos textos, e a professora colaboradora orientou que os alunos confrontassem os textos que tinham em mãos a fim de que fizessem a seleção das informações contidas no acervo, buscando identificar dados mais recorrentes, assim como relações de pertinência ou continência entre as informações.

No módulo 2, os grupos, sempre assistidos pela professora colaboradora, foram orientados a trabalhar a recomposição das informações que foram decompostas do acervo. Conforme Gomes-Santos (2012, p.70), não basta apenas identificar e selecionar os conteúdos do acervo, faz-se necessário dar-lhes um tratamento novo, "uma configuração diferente daquela que aparece nos textos do acervo".

Assim sendo, ocorreu a ação de resumir ou sumarizar esses conteúdos escolhidos. Momento em que os alunos se questionam "o que fazer diante do conjunto de informações selecionadas? Como dar-lhes uma versão mais sintética e mais próxima daquilo que se intenciona expor efetivamente?" (GOMES-SANTOS, 2012, p. 70). Portanto, a recomposição recai sobre partes do texto com extensões variadas e se configura na síntese ou redução dessas partes, também é possível perceber uma outra ação que é a adaptação, "pela qual uma nova porção do texto é condensada em uma nova estrutura sintática" (GOMES-SANTOS, 2012, p.73). 
Consequentemente, nota-se que dentro da atividade de recomposição dos conteúdos, a tarefa de sumarizar é de fato bastante relevante para o planejamento da exposição, visto que é o momento em que o aluno irá demonstrar a forma como interpretou as informações do acervo e, além disso, pode ser considerada como um dispositivo que o aluno poderá utilizar em várias outras atividades escolares de estudo de textos.

Os alunos se envolveram bastante nas atividades e participaram ativamente da atividade proposta, tornando-se investigadores do acervo de informações sobre o assunto que iriam expor, exercitando, assim, habilidades relativas à leitura e compreensão textual.

As atividades trabalhadas no módulo 3 tiveram como foco aspectos relacionados a outras semioses, considerando dimensões corporais, cinésicas, paralinguísticas e prosódicas. Assim, os alunos participaram de uma oficina e realizaram atividades relativas à desinibição, correção de postura ao se apresentar, impostação da fala, destravamento da timidez, entre outros.

Diversas vezes, conforme ressalta Gomes-Santos (2012), aquilo que se pretende explicar como inibição ou timidez de muitos alunos que se sentem desconfortáveis ao falar em público pode estar relacionado à complexidade que a fala assume no momento da exposição oral, visto que a natureza multissemiótica da elocução do expositor exige a combinação de diferentes capacidades e habilidades.

Nas atividades deste módulo contamos com a participação de um profissional da área da comunicação, o qual envolveu a turma em sua oficina. Ele iniciou o processo chamando um aluno voluntário à frente da sala e pediu que se apresentasse de forma natural, sem qualquer intervenção, a fim de observar o seu nível de oratória. Em seguida, iniciou uma conversa com o grupo sobre pessoas que têm medo de falar em público, destacando que, na maioria das vezes, elas apresentam três características: a primeira é não se movimentar, a segunda é não encarar a plateia, a visão se volta para o chão ou qualquer objeto da sala, e isso ocorre pela insegurança de não se achar capaz de expor uma ideia com clareza. A 
terceira característica, também muito comum, é a gesticulação deficiente. Mãos no bolso, segurando algum objeto ou mesmo espremendo-as são indícios de insegurança e desconforto com a situação.

Após essa discussão, juntamente com a turma, foi analisada a performance dos alunos, o passo seguinte foi orientar e apresentar ferramentas para trabalhar cada uma das características citadas acima. A primeira intervenção foi em relação ao movimento, pediu-se que o aluno andasse de um lado ao outro, com o tronco levemente curvado indo em direção à plateia, notou-se resultado imediato. Outra ferramenta aplicada, também eficaz, foi pedir para que o aluno alinhasse a velocidade dos passos à fala, levando os espectadores a acompanharem o assunto.

$\mathrm{Na}$ sequência, foram desenvolvidas com os alunos atividades relacionadas à visão, pois em uma exposição oral encarar o auditório é primordial. O "olho no olho" transmite credibilidade à plateia e, como constatado na primeira produção, muitos alunos ao se exporem não encaravam os ouvintes, chegando até a olhar para o chão no momento de sua fala. A orientação para este momento foi manter visão direta com pessoas dispostas em pontos estratégicos da sala. O critério utilizado nesta escolha foi encontrar espectadores que se mostravam receptivos ao assunto, concordando com ele ao movimentar sua cabeça em sinal de "sim", ou seja, pessoas com feição leve ao acompanhar o assunto.

Por fim, foi trabalhada a gesticulação. Aqui a intervenção foi simples: apenas deixar um dos braços relaxado, paralelo ao tronco. Dessa forma, o outro braço fica livre para gesticular, evitando o encontro das mãos, espremendo-as, ou mesmo levando-as ao bolso.

Constatamos que essa intervenção foi fundamental no percurso da SD, pois essas ferramentas trabalhadas não agem separadamente na produção oral, ou seja, mantêm relações de interdependência e, inclusive, os alunos não absorvem essas técnicas sozinhos. É necessário capacitá-los a fim de que esses recursos sejam manejados pelo falante. 
Em síntese, observamos que houve real engajamento da turma nessa oportunidade de vivenciar novas experiências de se apresentar em público, ampliando as formas de se comunicar e deixando de conceber a comunicação oral como um entrave.

No módulo 4, o objetivo principal foi trabalhar a leitura de gêneros que envolvem a percepção de outras semioses, ou seja, articulam linguagem verbal e não verbal, com foco nos aspectos visuais dos textos, como charges e infográficos. A princípio, os grupos foram orientados pela professora colaboradora a pesquisarem na internet materiais referentes aos temas que estavam desenvolvendo na SD.

Dessa vez os próprios alunos pesquisaram, selecionaram os conteúdos e levaram para serem discutidos em sala de aula. Os alunos, em seus grupos, analisaram, confrontaram os materiais, selecionaram as informações mais significativas, planejaram e produziram um conteúdo, e posteriormente, sempre mediados pela professora colaboradora, iniciaram um debate em que todos os grupos expuseram sua pesquisa e puderam compartilhar ideias sobre os assuntos abordados. Nesse momento, os alunos realizaram o debate, trocando ideias e partilhando informações a respeito dos temas trabalhados.

No módulo 5, os grupos se envolveram em planejar e elaborar uma parte bastante significativa da exposição oral: o roteiro. Conforme Gomes-Santos (2012, p. 75), roteirizar tem o objetivo de "reagrupar o conjunto de informações selecionadas e sumarizadas, dispondo-as em um esquema que servirá de guia para o momento da exposição". Ao elaborar o roteiro da exposição, o expositor poderá proceder de duas formas: hierarquizar as informações, estabelecendo relações de subordinação entre informações principais e secundárias ou distribuir as informações na ordem que deseja apresentá-las à plateia.

Com a progressão da aprendizagem da exposição, segundo GomesSantos (2012), o aluno vai internalizando métodos cada vez mais eficientes de formular o roteiro da exposição e consequentemente, tendo 
maior domínio em relação à elaboração dessa tarefa. Sendo assim, trabalhamos o seguinte modelo de roteiro com os alunos: 1) Tema; 2) Local; 3) data/duração; 4) Público; 5) Objetivo; 6) Assunto; 7) Sequência: a) Apresentação do grupo, b) Por que escolheram o tema, c) Descrição do assunto; 8) Recursos: slides, cartazes, etc.; 9) Conclusão do tema; 10) Interação com o auditório e 11) Despedida/agradecimentos.

O primeiro item do roteiro é o tema, ou seja, o assunto a ser apresentado pelo grupo, o qual já havia sido decidido, conjuntamente, conforme descrito na apresentação da situação de comunicação. O segundo é o local, as exposições ocorreriam em uma sala, próxima ao pátio da escola, a data foi previamente definida e as apresentações teriam duração de aproximadamente 10 minutos por grupo. O público definido como auditório foi o $6^{\circ}$ ano, como já foi dito. Em seguida, o objetivo foi retomado com grupo, que discutiu sobre quais as intenções ao se apresentar determinada temática para o público alvo.

Quanto aos assuntos tratados, já havia sido acordado com os alunos que cada grupo trabalharia com três textos diferentes, dentro de cada assunto abordado, fazendo, conforme mencionado anteriormente, a decomposição e a recomposição do acervo de informações.

Já quanto à sequência, primeiramente, foi definida a ordem de apresentação dos componentes do grupo. Depois foi o momento de planejar o que relatar aos espectadores sobre o porquê de terem escolhido aquele tema específico, quais mensagens pretendiam transmitir aos alunos do $6^{\circ}$ ano. Por último, procederam à descrição do assunto, ou seja, os alunos planejaram e elencaram os itens que seriam expostos à plateia, hierarquizando e ordenando as informações.

Dando sequência à montagem do roteiro, os alunos, sempre orientados pela professora, discutiram sobre os recursos que utilizariam para complementar a apresentação: slides, cartazes, planfletos, entre outros.

O item seguinte do roteiro é a conclusão, momento em que o grupo discutiu sobre a finalização da exposição, por meio de uma síntese para dar 
início à etapa seguinte que é a interação com o auditório. Nessa parte, os alunos simularam perguntas que poderiam ser feitas à plateia e respostas que poderiam ser dadas aos questionamentos feitos pelo público. Por fim, chegou-se ao desfecho da exposição, em que os alunos puderam compartilhar e exercitar recursos formais de despedida e de agradecimento à atenção recebida do auditório.

Com base, então, no trabalho realizado com todos esses itens, cada grupo elaborou o seu próprio roteiro da exposição oral. Após essa atividade, os grupos já demonstravam maior domínio das habilidades de uso da linguagem verbal e não verbal para a produção da exposição oral.

Por fim, o módulo 6 teve como principal objetivo fazer com que os alunos se apresentassem para a própria sala, como um ensaio para a produção final. A professora colaboradora mediou o ensaio dos grupos, fez algumas intervenções durante as apresentações, orientando os alunos quanto às falas, se os conteúdos trabalhados pelos grupos estavam pertinentes à exposição, se havia sequência nos conteúdos, coesão interna nos grupos, como ocorriam as trocas de fala, entre outros. Isto para que os alunos pudessem realizar a produção final com maior domínio do gênero, adequado à situação comunicativa real proposta.

Após a realização dos 6 módulos, os grupos realizaram, então, a produção final, momento de verificarmos se os alunos avançaram em relação às dificuldades apresentadas na primeira produção. Conforme Dolz, Noverraz e Schneuwly (2004, p.90), esta é a "possibilidade de pôr em prática as noções e os instrumentos elaborados separadamente nos módulos".

Nesta última etapa da SD, os grupos apresentaram-se em uma sala que possuía TV e computador, sendo possível projetar os slides, para os alunos do $6^{\circ}$ ano, a audiência. Da mesma forma que ocorreu na primeira produção, as exposições foram gravadas e posteriormente transcritas e analisadas, evidenciando-se que não apenas a representação da materialidade fônica foi considerada significativa, mas também, a performance das semioses não verbais, como: os movimentos corporais, os 
olhares, os gestos, inclusive o contexto no qual as exposições dos alunos ocorreram, relacionadas às práticas sociais e de linguagem.

Foi evidente, na produção final, após as intervenções didáticas nos módulos, que a performance dos alunos havia evoluído. Realmente, incorporaram o papel de expositor, reavaliaram a postura, o entrosamento entre si, articulando recursos verbais, não verbais e prosódicos, inclusive envolvendo a plateia com indagações.

Com base na mesma grade de análise (Quadro 1), foi possível notar avanços em relação às inúmeras dificuldades apresentadas pelos grupos durante a exposição da primeira produção. Por exemplo, os grupos apresentaram-se dando maior importância à plateia, passaram a encarar o auditório, questionando se havia dúvidas, tentando reformular elementos mais complexos. As trocas de fala entre os colegas ocorreram de maneira mais formal. Em relação à linguagem, os alunos passaram a utilizar recursos mais formais, evitando gírias, aumentaram o tom de voz, falando pausadamente, utilizaram slides e cartazes como recursos visuais.

Em relação à abordagem do conteúdo temático, os temas focalizados, selecionados pelos próprios alunos, despertaram o interesse do público-alvo, levando-os a refletir sobre assuntos relacionados ao seu dia a dia e, assim, atendendo aos objetivos da exposição oral.

Com a mobilização de materiais oriundos de fontes diversificadas, os grupos conseguiram estruturar melhor os conteúdos expostos, separando ideias principais das secundárias, utilizando exemplos. As informações estavam articuladas, ocasionando encadeamento no fluxo de ideias e consequentemente entendimento pelo auditório.

Em se tratando da estrutura composicional da exposição, os alunos assumiram o papel de expositores pois se apresentaram, realizaram saudação ao auditório e anunciaram o tema da exposição, criando interação com os alunos do $6^{\circ}$ ano, os quais assumiam o papel de audiência. Ao iniciarem as exposições, os grupos passaram a encarar o auditório de forma diferente, ou seja, como seu público interlocutor. Utilizaram-se dos 
indicadores das fases de abertura e de introdução ao tema, por exemplo: "bom dia, pessoal”; "a gente vai começar"; "esses são os integrantes do nosso grupo"; "pesquisamos sobre ..."; "agora eu vou falar sobre ...”.

Assim, a introdução ao tema foi realizada de forma a captar a atenção da plateia, justificando sua relevância. Os expositores fizeram questionamentos ao auditório relacionados ao tema, levando a plateia a refletir sobre certos assuntos.

Os grupos planejaram um roteiro e seguiram suas etapas durante a exposição, apresentando as ideias de forma sequenciada. Os expositores se preocuparam em sumarizar o conjunto de conteúdos expostos. Os grupos anunciaram o final da exposição, houve agradecimentos ao auditório, e questionaram se havia perguntas a serem feitas. Os expositores previam as dificuldades da audiência e reformulavam as partes mais complexas, explicando-as ou parafraseando-as. Os alunos articularam linguagem verbal não verbal, utilizando recursos visuais, como cartazes e slides. Enfim, todos os alunos passaram a dominar o conteúdo, desenvolvendo-o com autonomia e desenvoltura, não tendo mais cópias em mãos para leitura. Notou-se também entrosamento dos expositores com o auditório. Estes se preocuparam com o entendimento da plateia, abriram espaço para os questionamentos e faziam retomada de assunto já mencionado.

Referindo-se aos aspectos paralinguísticos, percebeu-se que o tom de voz dos alunos tornou-se audível, passaram a se expor com maior firmeza, mostrando-se bem mais confortáveis e seguros durante a exposição. Houve presença de recursos prosódicos, com monitoramento das falas e particularidades importantes, como pausas e variação no tom de voz, foram trazidas à exposição, atribuindo clareza e coerência ao conteúdo como um todo. A apresentação mais articulada normalizou o ritmo das falas, visto que estas estavam mais espaçadas, configurando um conteúdo bem mais natural e progressivo à exposição.

Os meios cinésicos tornaram-se presentes, os alunos atentavam-se à postura corporal, adotaram movimentação dos braços e cabeça de forma a 
enfatizar o que estava sendo enunciado, com direcionamento do olhar para o auditório, ou seja, os grupos se preocuparam em criar interação com os ouvintes. Houve domínio de palco, os alunos se colocaram um ao lado do outro, mas se movimentavam e se destacavam no momento de suas falas.

As trocas e as retomadas de falas ocorreram de maneira articulada, pois os alunos dominavam o conteúdo como um todo e sabiam o exato momento de se pronunciar. Houve, também, complementariedade entre as falas, promovendo a construção de sentido do texto.

Em suma, considerando os resultados da análise da produção final, verificamos que houve avanço nas capacidades de linguagem dos alunos na produção de um gêneros oral formal, a exposição oral. Com isso, evidencia-se que o dispositivo da SD contribuiu, de fato, para tais avanços.

\section{Conclusão}

Conforme mencionado na Introdução, neste trabalho, nossa intenção foi apontar contribuições do uso do dispositivo SD de gêneros textuais para o desenvolvimento das capacidades de linguagem oral formal dos alunos, nos anos finais do Ensino Fundamental.

Por meio da descrição do processo de construção colaborativa, entre professora pesquisadora e professora colaboradora, buscamos evidenciar avanços dos alunos na produção final da exposição oral, comparando-se com a primeira produção, a qual nos serviu para diagnosticar o que os alunos necessitavam aprender.

Inicialmente, foi possível perceber as dificuldades dos alunos em relação aos gêneros textuais orais formais, pelo fato de ser algo novo para eles ou por não terem tido a oportunidade de serem protagonistas do processo de ensino e de aprendizagem, com autonomia para selecionar textos sobre os temas a serem apresentados, para organizar e expor as informações a um público real, em uma situação comunicativa autêntica, real.

A análise das duas produções, antes e após a realização dos módulos evidenciou que, no processo de construção da SD, os alunos são considerados 
protagonistas do processo de ensino e aprendizagem; o envolvimento dos alunos em contextos reais de produção possibilita-lhes melhor aprendizagem; a construção do conhecimento pedagógico do conteúdo das professoras, na/sobre a prática em sala de aula, contribui para o seu desenvolvimento profissional e dá mais autoria ao trabalho docente.

Por fim, concluímos que considerar os gêneros orais formais como objeto de ensino de Língua Portuguesa, na Educação Básica, além de valorizar a língua oral, atribui às aulas um caráter mais significativo, amplia as capacidades de linguagem oral dos alunos, preparando-os para participar de forma efetiva nas diversas esferas comunicacionais presentes em nossa sociedade.

\section{Referências}

APARÍCIO, A. S. M. e ANDRADE, M. F. R. de A construção colaborativa de sequências didáticas de gêneros textuais: uma estratégia inovadora de formação docente. In: Marli André (org.) Práticas Inovadoras na Formação de Professores, Campinas. SP: Papirus, 2016, p.71.

BAKHTIN, M. Os gêneros do discurso. Estética da criação verbal. v. 4, p. 261306, 2006.

BRASIL. Ministério da Educação. Secretaria de Educação Fundamental. Parâmetros Curriculares Nacionais: Língua Portuguesa/Secretaria de Educação Fundamental. Brasília: Ministério da Educação, 1998.

BRASIL. Ministério da Educação. Secretaria de Educação Básica. Base Nacional Comum Curricular. Brasília: Ministério da Educação,2017.

DAMIANI, M. F. Sobre pesquisas do tipo intervenção. In: XVI Encontro Nacional de Didática e Prática de Ensino, 2012, Campinas. Anais do XVI Encontro Nacional de Didática e Prática de Ensino. Campinas: UNICAMP, 2012. p. 1-9.

DOLZ, J.; NOVERRAZ, M.; SCHNEUWLY, B. Sequências didáticas para o oral e a escrita: apresentação de um procedimento. In: SCHNEUWLY, B.; DOLZ, J. Gêneros orais e escritos na escola. In: Campinas: Mercado de Letras, 2004. 
DOLZ, J.; SCHNEUWLY, B.; HALLER, S. O oral como texto: como construir um objeto de ensino. In: SCHNEUWLY,B.; DOLZ, J. Gêneros orais e escritos na escola. In: Campinas: Mercado de Letras, 2004, p.125-155.

DOLZ, J.; GAGNON, R.; DECÂNDIO, F. Produção escrita e dificuldades de aprendizagem. Campinas. SP: Mercado de Letras, 2010.

GOMES-SANTOS, S. N. A exposição oral: nos anos iniciais do ensino fundamental. São Paulo: Cortez, 2012.

GOULART, C. As práticas orais na escola: o seminário como objeto de ensino. 2005. 210f. Dissertação (Mestrado) - Universidade Estadual de Campinas (UNICAMP) - Campinas, 2005.

GOULART, C. A caracterização do gênero exposição oral no contexto das práticas de linguagem na escola. Olhares \& Trilhas. Uberlândia, vol. 19, n. 2, jul./dez. 2017. DOI: https://doi.org/10.14393/OT2017v19.n.2.230-258.

GUIMARÃES, A. M. de M.; SOUZA, J. de. Pela necessidade de trabalhar a oralidade na sala de aula. Diálogo das Letras, Pau dos Ferros, v. 7, n. 2, p. 81 - 100, maio/ago. 2018. DOI: https://doi.org/10.22297/dl.v7i2.3207.

MAGALHÃES, T. G. Oralidade na sala de aula: alguém "fala" sobre isso? Revista Instrumento: Revista de Estudo e Pesquisa em Educação. EDUFJF, v. $7 / 8,2005 / 2006$.

MARCUSCHI, L.A.. Da fala para a escrita: atividades de retextualização. São Paulo: Cortez, 2007.

SCHNEUWLY,B; DOLZ, J. Gêneros orais e escritos na escola. Campinas, SP: Mercado de Letras, 2004. 